\title{
Geltung der allgemeinen Steuergesetze
}

Soweit sich aus den Kirchensteuergesetzen der Länder bzw. den Steuerordnungen der steuererhebenden Körperschaften nichts anderes ergibt, finden die Vorschriften der Abgabenordnung entsprechende Anwendung. Nicht anzuwenden sind die Vorschriften über die Verzinsung ( $\$ § 233$ bis 239 AO), die Säumniszuschläge ( $\$ 240$ AO), und das Straf- und Bußgeldverfahren $(\$ \S 369 \text { bis } 412 \mathrm{AO})^{1}$ sowie ggfs. über das außergerichtliche Rechtsbehelfsverfahren ( $\S 347$ bis $368 \mathrm{AO})$.

Sofern die Festsetzung und Erhebung der Kirchensteuer den Finanzämtern übertragen (Regelfall) oder von den Gemeinden, Landkreisen oder deren Hebestellen übernommen ist (z. B. bei der Kirchensteuer nach den Grundsteuermessbeträgen), so finden auf die

1. als Steuer vom Einkommen und als Kirchgeld nach Maßgabe des Einkommens zu erhebende Kirchensteuer die Vorschriften für die Einkommensteuer, insbesondere die Vorschriften über das Lohn- und Kapitalertragsteuer-Abzugsverfahren,

2. als Steuer vom Vermögen zu erhebende Kirchensteuer die Vorschriften für die Vermögensteuer und

3. als Steuer vom Grundbesitz zu erhebende Kirchensteuer die Vorschriften für die Grundsteuer entsprechende Anwendung.

\section{Literatur}

Rönnau, Thomas. 1995. Die Verkürzung von Kirchensteuern - ein Betrug ohne Folgen? wistra 14:47-50.

${ }^{1}$ Zur Frage der Strafbarkeit s. Rönnau, wistra 1995, 47; BGH v. 17.4.2008, 5 StR 547/07, Wistra 2008, 310. Zur Vollstreckung der Kirchensteuer im Ausland s. BMF v. 23.1.2014, BStB1. I 2014, 188. 